\title{
Vaccination Coverage Among Children in Kindergarten - United States, 2015-16 School Year
}

\author{
Ranee Seither, $\mathrm{MPH}^{1}$; Kayla Calhoun, $\mathrm{MS}^{1}$; Jenelle Mellerson, $\mathrm{MPH}^{1}$; Cynthia L. Knighton ${ }^{1}$; Erica Street, $\mathrm{MPH}^{1,2}$;
} Vance Dietz, $\mathrm{MD}^{1}$; J. Michael Underwood, $\mathrm{PhD}^{1}$

State-mandated vaccination requirements for school entry protect children and communities against vaccine-preventable diseases (1). Each school year, federally funded immunization programs (e.g., states, territories, jurisdictions) collect and report kindergarten vaccination data to CDC. This report describes vaccination coverage estimates in all 50 states and the District of Columbia (DC), and the estimated number of kindergartners with at least one vaccine exemption in 47 states and DC, during the 2015-16 school year. Median vaccination coverage* was $94.6 \%$ for 2 doses of measles, mumps and rubella vaccine (MMR); $94.2 \%$ for diphtheria, tetanus, and acellular pertussis vaccine $(\mathrm{DTaP})$; and $94.3 \%$ for 2 doses of varicella vaccine. MMR coverage increased in 32 states during the last year, and 22 states reported coverage $\geq 95 \%$ (2). A total of 45 states and DC had either a grace period allowing students to attend school before providing documentation of vaccination or provisional enrollment that allows undervaccinated students to attend school while completing a catch-up schedule. Among the 23 states that were able to voluntarily report state-level data on grace period or provisional enrollment to CDC, a median of $2.0 \%$ of kindergartners were not documented as completely vaccinated and were attending school within a grace period or were provisionally enrolled. The median percentage of kindergartners with an exemption from one or more vaccinations $^{\dagger}$ was $1.9 \%$. State and local immunization programs, in cooperation with schools, can improve vaccination coverage by ensuring that all kindergartners are vaccinated during the grace period or provisional enrollment.

Federally funded immunization programs in 50 states and DC partner with departments of education, school nurses, and other school personnel to assess vaccination coverage and exemption status of children enrolled in public and private kindergartens. ${ }^{\S}$ Eight states reported data for some homeschooled

\footnotetext{
* Median vaccination coverage was determined using estimates from the 50 states and DC.

${ }^{\dagger}$ Median exemption rate was determined using estimates from 47 states and DC; states excluded were Illinois, Minnesota, and Missouri. Data from Wyoming were included in the median for any exemption, but not for medical or nonmedical exemptions.

$\$$ Assessment date varied by state/area.
}

kindergartners. 9 During the 2015-16 school year, for the first time, 23 states reported data on children who were neither fully vaccinated nor exempt, but attending kindergarten under a grace period or provisional enrollment. A grace period is a set number of days during which a student can be enrolled and attend school without proof of complete vaccination or exemption. A provisional enrollment allows a student without complete vaccination or exemption to attend school while completing a catch-up vaccination schedule.

States use a range of data sources to assess vaccination coverage, and during the 2015-16 school year, vaccination assessments varied by immunization program because of differences in state mandates, data reported, and available resources. Among the 51 programs reporting data, 32 used a census to collect kindergarten vaccination data; 10 used a sample; three used a voluntary school response; and six used a mix of sampling methods.** Programs used the same methods to collect both vaccination coverage and exemption data, except for programs in Alaska, Kansas, New Mexico, and Virginia, which used a sample to collect vaccination coverage data and a census

\footnotetext{
I California included data for independent study students in public school data and data for homeschools with six or more students in private school data Minnesota requires vaccination and exemption reporting for homeschooled students beginning at age 7 years and reports these data separately from public and private school data, although the actual number of homeschooled students included in the data was not known. North Carolina included students enrolled in virtual academies in public school data. North Dakota reported that some public school jurisdictions included homeschooled students in their data. Oregon reported some homeschool data separately and children enrolled in public online homeschools were included in the public school data. Pennsylvania included all homeschooled students in their public school data. Utah included students enrolled in public and private online schools. Vermont included homeschooled students in their public and private school data if they were enrolled in one or more classes in those schools; homeschooled children who were exclusively homeschooled were not subject to vaccination requirements and were not included in these estimates.

** States using a census attempted to collect data from all kindergartners at all schools and succeeded with collecting data for $\geq 90 \%$ of students. The type of sample employed by the 10 states using a sample for determining coverage rates varied, and included a stratified two-stage cluster sample (eight states), a stratified one-stage cluster sample (one), and a simple random sample (one). A voluntary response of schools was defined as census survey with a response rate $<90 \%$ of the known population of kindergartners. A mix of methods included two or more described methods, usually a census for one school type and voluntary response for the other.
} 
for exemption data. Six states (Colorado, Delaware, Hawaii, Nevada, South Carolina, and Wisconsin) used a sample for both vaccination coverage and exemption data. Kindergartners were considered up-to-date for a vaccine if they received all doses required for school entry, ${ }^{\dagger \dagger}$ except in seven states ${ }^{\$ \$}$ that considered kindergartners up-to-date only if they had received all doses of all vaccines required for school entry.

Kindergartners with a history of varicella disease were reported as either vaccinated against varicella or medically exempt, varying by program. Medical exemptions were those that were issued by a health care provider; all other exemptions (i.e., religious and philosophic) were nonmedical. Vaccination coverage and exemption estimates were adjusted based on survey type and response rates. 99

During the 2015-16 school year, vaccination coverage data were reported for 4,087,187 kindergartners, exemption data for 3,791,755 kindergartners, and grace period/ provisional enrollment data for 2,173,042 kindergartners.*** Among the 50 states and DC, median MMR coverage was 94.6\% (range $=87.1 \%$ [Colorado] to $99.4 \%$ [Maryland and Mississippi]); 22 states reported coverage $\geq 95 \%$, and three states and DC reported coverage $<90 \%$ (Table 1). Among 49 states and $\mathrm{DC}$ that require $\mathrm{DTaP}$ vaccination, median coverage was $94.2 \%$ (range $=86.6 \%$ [Colorado] to $99.6 \%$ [Maryland]); 20 states reported coverage $\geq 95 \%$, and four states and DC reported coverage $<90 \%$. Among 42 states and DC that required 2-dose varicella vaccination, median coverage was 94.3\% (range $=85.7 \%$ [Colorado] to 99.4\% [Mississippi]); 18 states reported coverage $\geq 95 \%$, and five states and DC

${ }^{\dagger \dagger}$ All the 50 states and DC required 2 doses of a measles-containing vaccine, with MMR as the only measles-containing vaccine available in the United States. For local DTaP vaccine requirements, Nebraska required 3 doses, four states (Illinois, Pennsylvania, Virginia, and Wisconsin) required 4 doses, Pennsylvania did not require pertussis, and all other states required 5 doses unless the fourth dose was administered on or after the fourth birthday. Kentucky required 5 doses of DTaP by age 5 , but reported 4-dose coverage for kindergartners. For varicella vaccine, eight states required 1 dose and 42 states and DC required 2 doses.

$\$ \$$ Alabama, Florida, Georgia, Iowa, Mississippi, New Hampshire, and New Jersey considered kindergartners up-to-date only if they had received all doses of all vaccines required for school entry.

99 Most of the programs using a census or voluntary response provided CDC with data aggregated at the state level. Coverage and exemption data based on a census were adjusted for nonresponse using the inverse of the response rate, stratified by school type. Programs using complex sample surveys provided CDC with de-identified data aggregated at the school or county level for weighted analysis. Weights were calculated to account for sample design and adjusted for nonresponse for data collected by complex sample design wherever possible.

*** Immunization programs in U.S. territories reported vaccination coverage and exemptions to CDC. Their data were not included in median coverage and exemption calculations. Select U.S. cities also reported data to CDC, which were included in state-reported data to calculate medians. reported coverage $<90 \%$. The number of states requiring 2 doses of varicella vaccine for school entry increased from 39 in 2014-15 to 42 in 2015-16. Median 2-dose varicella coverage increased from $93.6 \%$ to $94.3 \%$, in part because of high coverage in three states that added a requirement for 2 doses of varicella vaccine (Montana [93.6\%]; North Carolina [97.0\%]; and Utah [94.8\%]) (3).

Since the 2014-15 school year, MMR coverage increased in 32 states (2). Compared with 2014-15, among states that reported coverage for both 2014-15 and 2015-16, four fewer states reported $<90 \%$ MMR coverage, and five more states reported $\geq 95 \%$ MMR coverage in 2015-16 (Figure). The median increase was 0.7 percentage points (range $=0.1$ [Wyoming] to 4.1 [Oklahoma]) (2).

Twenty-three ${ }^{\dagger \dagger}$ states voluntarily reported data on grace period or provisional enrollment for the 2015-16 school year. The median reported percentage of kindergartners attending school during a grace period or provisional enrollment was $2.0 \%$ (range $=0.0 \%$ [Wyoming] to $5.4 \%$ [New Hampshire] (Table 2). In 12 of these 23 states, the percentage of children who were provisionally enrolled or within a grace period at the time of the assessment exceeded the percentage of children with exemptions from one or more vaccines.

Among the 47 states and DC reporting kindergartners with at least one exemption, the median was $1.9 \%$ (range $=<0.1 \%$ [Mississippi] to $6.3 \%$ [Oregon]), an increase of 0.2 percentage points from the previous year (Table 2). The percentage of kindergartners with any exemption was $<1 \%$ in six states, and $\geq 4 \%$ in nine states. From the 2014-15 to the 2015-16 school year, the exemption rate decreased by $>1.0$ percentage points in three states (Colorado, Michigan, and Wisconsin), and increased by $>0.5$ percentage points in two states (Nevada and North Dakota). The number of states with exemption rates $\geq 4.0 \%$ decreased from 11 in 2014-15 to nine in 2015-16. Michigan reported a 1.7 percentage point decrease in exemptions. Among states that reported exemptions by type, the median percentage of medical exemptions was $0.2 \%$ (range $=<0.1 \%$ in four states [Colorado, Delaware, Mississippi, South Carolina] to $1.2 \%$ [Alaska]), and the median percentage of nonmedical exemptions was $1.6 \%$ (range $=0.4 \%[\mathrm{DC}]$ to $6.2 \%$ [Oregon]). During $2015-16$, a total of 25 states ${ }^{\$ \$ \$}$ share or plan to share

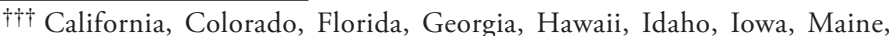
Mississippi, Montana, Nebraska, Nevada, New Hampshire, New Jersey, New Mexico, Pennsylvania, Tennessee, Texas, Utah, Vermont, Washington, West Virginia, and Wyoming reported data on kindergartners attending school under a grace period or provisional enrollment.

$\$ \$ \$$ http://www.cdc.gov/vaccines/imz-managers/SchoolVaxView/pubs-resources.html.
} 
TABLE 1. Estimated vaccination coverage* among children enrolled in kindergarten, by vaccine and state/area — United States, $2015-2016$ school year

\begin{tabular}{|c|c|c|c|c|c|c|c|c|}
\hline \multirow[b]{2}{*}{ State/Area } & \multirow[b]{2}{*}{$\begin{array}{c}\text { Kindergarten } \\
\text { population }^{\dagger}\end{array}$} & \multirow[b]{2}{*}{$\begin{array}{c}\text { Total } \\
\text { surveyed }\end{array}$} & \multirow[b]{2}{*}{$\begin{array}{c}\text { Proportion } \\
\text { surveyed (\%) }\end{array}$} & \multirow[b]{2}{*}{ Type of survey conducted ${ }^{\S}$} & \multirow{2}{*}{$\begin{array}{l}\text { MMR }^{\text {I }} \\
2 \text { doses } \\
(\%)\end{array}$} & \multirow{2}{*}{$\begin{array}{l}\text { DTaP** } \\
5 \text { doses } \\
(\%)\end{array}$} & \multicolumn{2}{|c|}{ Varicella } \\
\hline & & & & & & & $\begin{array}{c}1 \text { dose } \\
(\%)\end{array}$ & $\begin{array}{c}2 \text { doses } \\
(\%)\end{array}$ \\
\hline Median $^{+t}$ & & & & & 94.6 & 94.2 & 96.1 & 94.3 \\
\hline Alabama ${ }^{\S \S}$ & 60,392 & 60,392 & 100.0 & Census & $\geq 93.1$ & $\geq 93.1$ & $\geq 93.1$ & NReq \\
\hline Alaska $\Upsilon_{1, * * *}$ & 9,937 & 772 & 7.8 & Stratified 2-stage cluster sample & 93.5 & 92.8 & NReq & 92.6 \\
\hline Arizona $\S^{\S}$ & 83,088 & 83,088 & 100.0 & Census & 94.2 & 94.2 & 96.7 & NReq \\
\hline Arkansas ${ }^{\dagger \dagger \dagger}$ & 40,258 & 38,480 & 95.6 & Census (public); voluntary response (private) & 90.8 & 88.2 & NReq & 90.6 \\
\hline California ${ }^{+\dagger}$ & 593,788 & 551,123 & 92.8 & Census & 94.5 & 94.2 & 96.3 & NReq \\
\hline Colorado & 69,137 & 350 & 0.5 & Simple random sample & 87.1 & 86.6 & NReq & 85.7 \\
\hline Connecticut $\$ \S$ & 39,533 & 39,533 & 100.0 & Census & 97.0 & 97.0 & NReq & 96.6 \\
\hline Delaware & 11,589 & 1,103 & 9.5 & Stratified 2-stage cluster sample & 97.6 & 98.0 & NReq & 97.6 \\
\hline District of Columbia $\S$ & 8,080 & 8,080 & 100.0 & Census & 88.5 & 88.2 & NReq & 88.1 \\
\hline Florida $\S \S$, १ๆ & 224,430 & 224,430 & 100.0 & Census & $\geq 93.7$ & $\geq 93.7$ & NReq & $\geq 93.7$ \\
\hline Georgia§§ & 131,403 & 131,403 & 100.0 & Census & $\geq 94.6$ & $\geq 94.6$ & NReq & $\geq 94.6$ \\
\hline Hawaii & 16,325 & 1,098 & 6.7 & Stratified 2-stage cluster sample & 91.6 & 93.8 & 95.4 & NReq \\
\hline Idaho $§ \S$ & 22,686 & 22,686 & 100.0 & Census & 90.2 & 89.8 & NReq & 89.1 \\
\hline Illinois $\S \S$ & 151,309 & 151,309 & 100.0 & Census & 94.9 & 95.0 & NReq & 95.5 \\
\hline Indiana & 83,525 & 58,062 & 69.5 & Voluntary response & 89.2 & 92.6 & NReq & 88.0 \\
\hline lowa & 41,215 & 41,215 & 100.0 & Census & $\geq 91.8$ & $\geq 91.8$ & NReq & $\geq 91.8$ \\
\hline 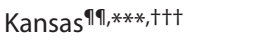 & 39,555 & 8,304 & 21.0 & Stratified 2-stage cluster sample & 89.4 & 89.4 & NReq & 87.9 \\
\hline Kentucky & 54,353 & 54,075 & 99.5 & Census & 92.2 & 93.9 & NReq & 91.6 \\
\hline Louisiana§§ & 59,159 & 59,159 & 100.0 & Census & 96.8 & 98.3 & NReq & 96.8 \\
\hline Maine & 13,526 & 12,243 & 90.5 & Census & 95.1 & 96.1 & 96.1 & NReq \\
\hline Maryland ${ }^{t+\dagger}$ & 72,012 & 67,903 & 94.3 & Census (public); voluntary response (private) & 99.4 & 99.6 & NReq & 99.2 \\
\hline Massachusetts ${ }^{\S \S, t+\dagger}$ & 72,897 & 72,897 & 100.0 & Census & 96.4 & 94.9 & NReq & 95.8 \\
\hline Michigan $\S \S$ & 116,299 & 116,299 & 100.0 & Census & 95.7 & 95.9 & NReq & 95.2 \\
\hline Minnesota ๆथा & 69,710 & 68,143 & 97.8 & Census & 92.8 & 93.0 & NReq & 92.3 \\
\hline Mississippi§§ & 41,042 & 41,042 & 100.0 & Census & $\geq 99.4$ & $\geq 99.4$ & NReq & $\geq 99.4$ \\
\hline Missouri§§,११ & 74,413 & 74,413 & 100.0 & Census & 95.7 & 95.6 & NReq & 95.4 \\
\hline Montana ${ }^{\S}$ & 11,484 & 11,484 & 100.0 & Census & 94.9 & 94.0 & NReq & 93.6 \\
\hline Nebraska ${ }^{\S \S,+† \dagger}$ & 30,409 & 30,409 & 100.0 & Census & 95.6 & 96.8 & NReq & 97.3 \\
\hline Nevada & 37,118 & 1,222 & 3.3 & Stratified 2-stage cluster sample & 94.7 & 94.2 & NReq & 93.4 \\
\hline New Hampshire & 11,852 & 11,831 & 99.8 & Census & $\geq 91.9$ & $\geq 91.9$ & NReq & $\geq 91.9$ \\
\hline New Jersey §§ & 110,116 & 110,116 & 100.0 & Census & $\geq 96.3$ & $\geq 96.3$ & $\geq 96.3$ & NReq \\
\hline New Mexico*** & 29,049 & 774 & 2.7 & Stratified 2-stage cluster sample & 96.2 & 94.7 & NReq & 95.8 \\
\hline $\begin{array}{l}\text { New York (including } \\
\text { New York City) }\end{array}$ & 232,521 & 232,521 & 100.0 & Census & 95.6 & 94.1 & NReq & 94.8 \\
\hline New York City $\S \S$ & 104,621 & 104,621 & 100.0 & Census & 94.6 & 91.9 & NReq & 93.5 \\
\hline 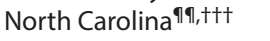 & 128,290 & 117,971 & 92.0 & Census (public); voluntary response (private) & 97.3 & 97.1 & NReq & 97.0 \\
\hline North Dakota & 9,875 & 9,586 & 97.1 & Census & 90.7 & 90.8 & NReq & 90.4 \\
\hline Ohio & 144,604 & 135,434 & 93.7 & Census (public); voluntary response (private) & 92.1 & 92.1 & NReq & 91.5 \\
\hline Oklahoma ${ }^{\dagger+\dagger}$ & 54,335 & 52,215 & 96.1 & Census & 94.4 & 96.1 & NA & NReq \\
\hline Oregon $\S \S,+† \dagger$ & 45,531 & 45,531 & 100.0 & Census & 93.9 & 93.5 & 95.2 & NReq \\
\hline Pennsylvania & 143,298 & 133,604 & 93.2 & Census (public); voluntary response (private) & 95.5 & NReq ${ }^{\S \S \S}$ & NReq & 96.5 \\
\hline Rhode Island $\$ \S$, ११, +†† & 11,165 & 11,163 & 100.0 & Census & 96.4 & 96.8 & NReq & 96.0 \\
\hline South Carolina & 59,240 & 5,251 & 8.9 & Stratified 1-stage cluster sample & 96.5 & 97.0 & NReq & 96.2 \\
\hline South Dakota $\S \S$ & 12,181 & 12,181 & 100.0 & Census & 96.5 & 96.4 & NReq & 95.2 \\
\hline 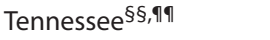 & 79,233 & 79,233 & 100.0 & Census & 93.5 & 93.5 & NReq & 93.5 \\
\hline $\begin{array}{l}\text { Texas (including } \\
\text { Houston) }{ }^{q \uparrow,++\dagger}\end{array}$ & 394,801 & 389,604 & 98.7 & Census (public); voluntary response (private) & 97.6 & 97.4 & NReq & 97.2 \\
\hline Houston, $T X^{91,+t \dagger}$ & 42,173 & 41,509 & 98.4 & Census & 96.5 & 96.6 & NReq & 96.0 \\
\hline Utah $\S \S$ & 50,114 & 50,114 & 100.0 & Census & 94.2 & 93.7 & NReq & 94.8 \\
\hline Vermont ${ }^{\S \S}$ & 6,366 & 6,366 & 100.0 & Census & 93.6 & 93.6 & NReq & 91.9 \\
\hline Virginia१११,**** & 100,074 & 4,304 & 4.3 & Stratified 2-stage cluster sample & 95.7 & 98.3 & NReq & 93.7 \\
\hline Washington ๆา & 86,492 & 84,155 & 97.3 & Census & 91.0 & 91.1 & NReq & 89.4 \\
\hline West Virginia & 21,333 & 18,690 & 87.6 & Voluntary response & 95.2 & 94.8 & NReq & 94.3 \\
\hline Wisconsin $19,++\dagger$ & 70,220 & 1,375 & 2.0 & Stratified 2-stage cluster sample & 93.2 & 96.9 & NReq & 92.5 \\
\hline Wyoming ๆศा,ศๆๆ & 7,825 & 5,791 & 74.0 & Voluntary response & 96.9 & 96.6 & NReq & 96.5 \\
\hline
\end{tabular}

See table footnotes on the next page. 
TABLE 1. (Continued) Estimated vaccination coverage* among children enrolled in kindergarten, by vaccine and state/area - United States, 2015-2016 school year

\begin{tabular}{|c|c|c|c|c|c|c|c|c|}
\hline \multirow[b]{2}{*}{ State/Area } & \multirow[b]{2}{*}{$\begin{array}{c}\text { Kindergarten } \\
\text { population }\end{array}$} & \multirow[b]{2}{*}{$\begin{array}{c}\text { Total } \\
\text { surveyed }\end{array}$} & \multirow[b]{2}{*}{$\begin{array}{l}\text { Proportion } \\
\text { surveyed (\%) }\end{array}$} & \multirow[b]{2}{*}{ Type of survey conducted ${ }^{\S}$} & \multirow{2}{*}{$\begin{array}{c}\text { MMR }^{\uparrow} \\
2 \text { doses } \\
(\%)\end{array}$} & \multirow{2}{*}{$\begin{array}{l}\text { DTaP** } \\
5 \text { doses } \\
(\%)\end{array}$} & \multicolumn{2}{|c|}{ Varicella } \\
\hline & & & & & & & $\begin{array}{c}1 \text { dose } \\
(\%)\end{array}$ & $\begin{array}{c}2 \text { doses } \\
(\%)\end{array}$ \\
\hline Guam*** & 2,715 & 780 & 28.7 & Stratified 2-stage cluster sample & 89.8 & 92.6 & NReq & NReq \\
\hline N. Mariana Islands $§ \S$ & 900 & 900 & 100.0 & Census & 89.8 & 77.7 & NReq & 89.9 \\
\hline Puerto Rico & 35,573 & 1,489 & 4.2 & Stratified 2-stage cluster sample & 96.5 & 92.9 & NReq & 95.4 \\
\hline U.S. Virgin Islands & 1,418 & 577 & 40.7 & Stratified 2-stage cluster sample & 87.2 & 85.6 & NReq & 86.9 \\
\hline
\end{tabular}

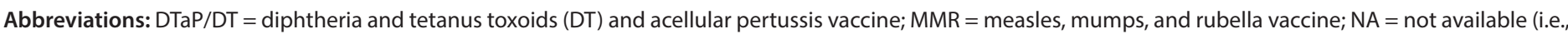
not collected or reported to $C D C)$; NReq = not required for school entry.

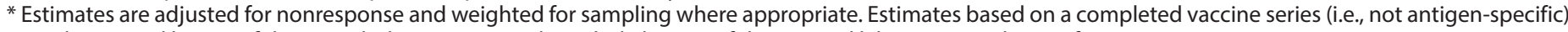
are designated by use of the $\geq$ symbol. Coverage might include history of disease and laboratory evidence of immunity.

† The kindergarten population is an approximation provided by each state/area.

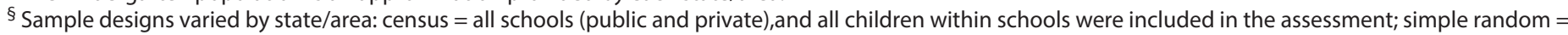

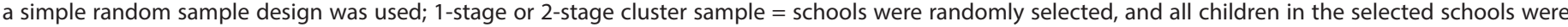

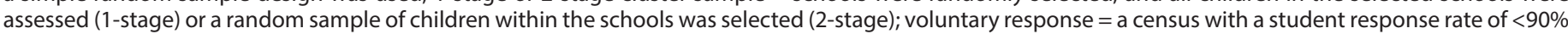
and does not imply that participation was optional.

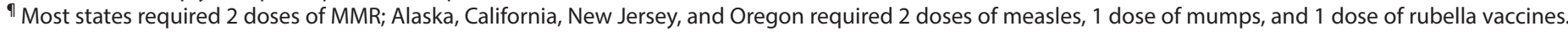

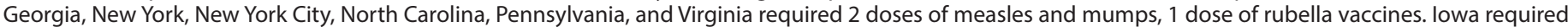
2 doses of measles and 2 doses of rubella vaccines.

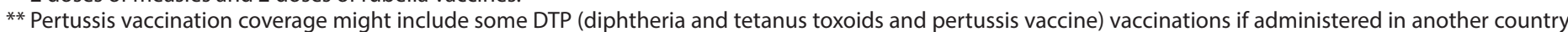

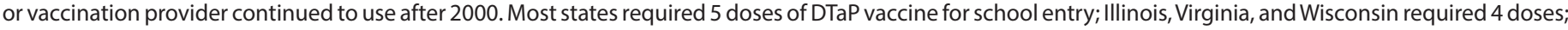

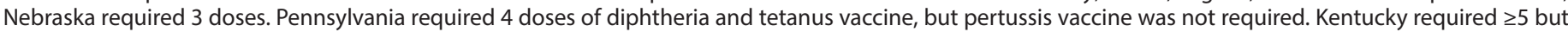
reported $\geq 4$ doses of DTaP.

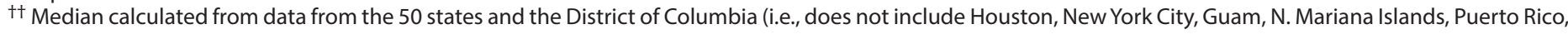
or U.S. Virgin Islands).

$\S \S$ The proportion surveyed was probably $<100 \%$, but shown as $100 \%$ based on incomplete information about the actual current enrollment.

१ๆ Did not include some special types of schools.

*** Kindergarten coverage data were collected from a sample, and exemption data were collected from a census of kindergartners.

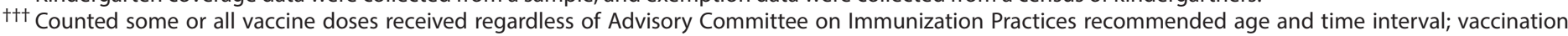
coverage rates shown might be higher than those for valid doses.

$\S \S \S$ Pertussis vaccine was not required in Pennsylvania. Coverage for diphtheria and tetanus was $96.3 \%$.

กศๆ Collected public school data only.

FIGURE. Estimated measles, mumps, and rubella vaccine (MMR) coverage among kindergartners — United States, 2014-15 and 2015-16 school years*,

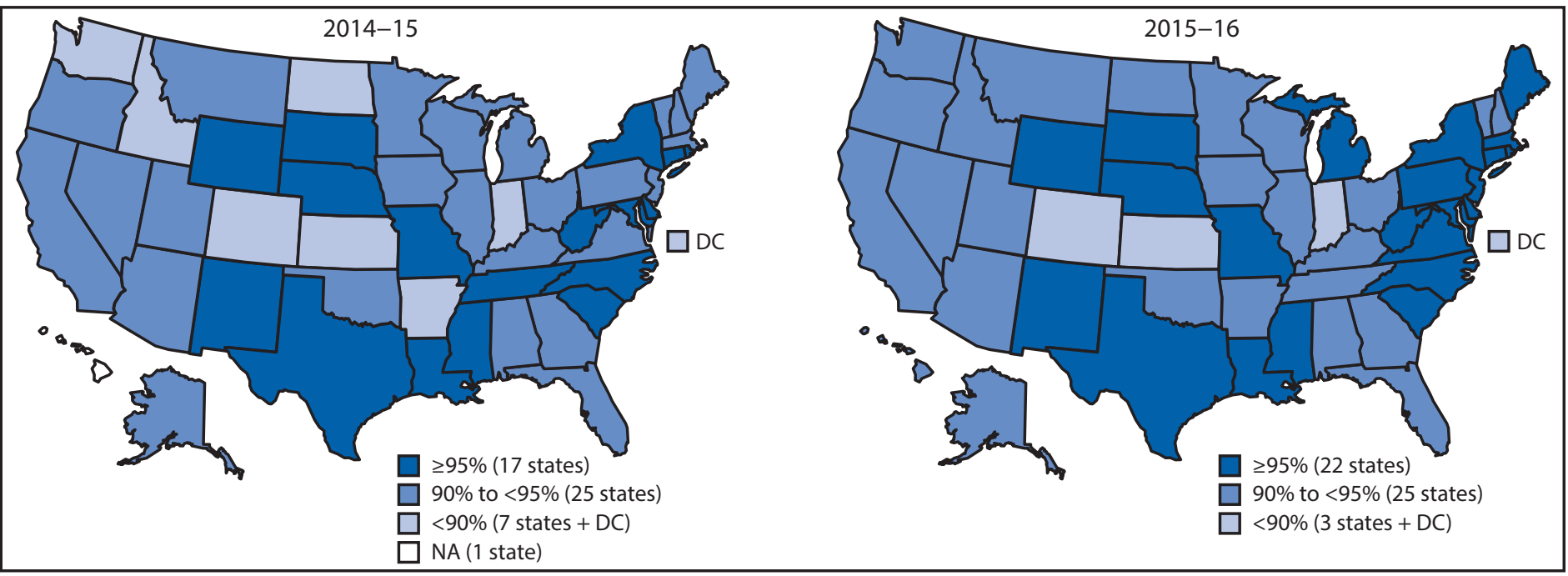

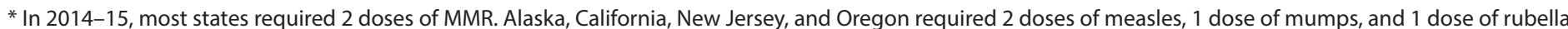

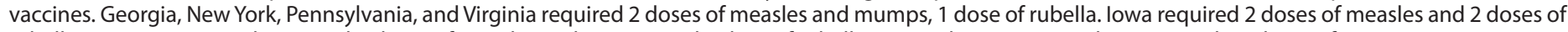
rubella vaccines. New York required 2 doses of measles and mumps and 1 dose of rubella vaccine by age 7 years, but reported $\geq 1$ doses of MMR.

† For 2014-15, Hawaii is excluded from the map because it reported compliance, rather than coverage.

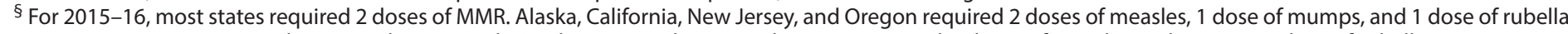

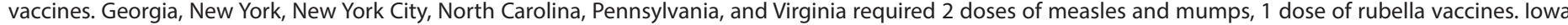
required 2 doses of measles and 2 doses of rubella vaccines. 
local-level data online for vaccination coverage, exemptions, or both, which is an increase from 21 states during 2014-15 (3).

\section{Discussion}

During the 2015-16 school year, median kindergarten vaccination coverage was nearly $95 \%$ for MMR $(94.6 \%)$, DTaP $(94.2 \%)$, and varicella vaccine $(94.3 \%)$, which was similar to the previous school year. MMR coverage increased for 32 states from the previous school year. The national median exemption rate of $1.9 \%$ was a slight increase from the previous school year $(1.7 \%)$, but only two states had an increase $>0.5$ percentage points in their state exemption rate and exemptions varied by state. The percentage of kindergartners who did not have complete documentation of vaccination, and who attended school within a grace period or were provisionally enrolled, was as high as $5.4 \%$ among the 23 states with data available.

Grace period and provisional enrollment, not collected in previous years, might in part explain results from previous years indicating that some children were enrolled in school but reported neither as vaccinated nor as exempt (3). Immunization programs can support and work with schools with high provisional enrollment and help students obtain missing vaccine doses. For example, the California Health Department worked to improve vaccination coverage at schools identified from local-level data as having high levels of provisional enrollment. School staff members were trained on the proper use of provisional enrollment (4). As a result, from $2014-15$ to $2015-16$, the number of provisionally enrolled kindergartners decreased from 36,731 (6.3\%) to 24,424 (4.4\%), MMR coverage increased from $92.6 \%$ to $94.5 \%$, and DTaP coverage increased from $92.4 \%$ to $94.2 \%$ (4). The decrease in the number of provisionally enrolled children in California and the increase in MMR and DTaP coverage demonstrates that state immunization programs and schools can use provisional enrollment data to boost school vaccination coverage.

The increase in MMR coverage observed among 32 states during the 2015-16 school year might be attributable in part to the 2015 measles outbreaks, which included a reported total of 159 persons from 18 states and DC, of whom approximately $80 \%$ were unvaccinated or had unknown vaccination status (5). Maintaining high vaccination coverage levels is important for measles control and elimination (G).

A slight increase ( 0.2 percentage points) in the median exemption rate from $2014-15$ to $2015-16$ is accounted for in part by the addition of reports from Texas (1.6\%) and Wyoming $(2.7 \%)$, neither of which reported the number of children with an exemption from one or more vaccines for the 2014-15 school year. The 1.7 percentage point decrease in exemptions reported by Michigan might be because of a new

\section{Summary \\ What is already known about this topic?}

Immunization programs conduct annual kindergarten vaccination assessments to monitor vaccination coverage among school children. Although state-level vaccination coverage is high and exemptions are low, some children in kindergarten remain undervaccinated.

What is added by this report?

Among the 50 states and the District of Columbia (DC), median vaccination coverage was $94.6 \%$ for 2 doses of measles, mumps, and rubella vaccine (MMR) and $94.2 \%$ for local requirements for diphtheria, tetanus, and acellular pertussis vaccine among 49 states and DC. Among the 42 states and DC with a 2-dose varicella vaccine requirement, varicella vaccine coverage was $94.3 \%$. Thirty-two states reported an increase in 2-dose MMR coverage. The median exemption level remained low (1.9\%) but exemption rates varied by state. In 12 of 23 states that reported data on grace period or provisional enrollment for children who were not fully vaccinated, the proportion of kindergartners under a grace period or provisional enrollment was higher than the proportion that were exempt from one or more vaccines.

What are the implications for public health practice?

Routine monitoring of vaccination coverage and exemptions among kindergartners at the state level is important to ensure all children are protected from vaccine-preventable diseases. Local-level data on school vaccination coverage, exemptions, and grace period/provisional enrollment are essential to help immunization programs identify schools with higher numbers of students who are not completely vaccinated and not exempt. Immunization programs and schools can use local level data to work together to improve vaccination coverage and protect all kindergartners from vaccine-preventable diseases.TABLE 1. Estimated vaccination coverage* among children enrolled in kindergarten, by vaccine and state/area — United States, 2015-2016 school year

state rule requiring parents who request exemptions to receive health education at a county health department about the risks for vaccine-preventable diseases and the benefits of vaccination (7). The greatest fluctuations in exemptions occurred among states that used samples to collect exemption data. Of the five states with an increase of $\geq 0.5$ percentage points or decrease of $\geq 1$ percentage points in exemptions since the previous school year, three (Colorado, Nevada, and Wisconsin) reported data from a sample of students. CDC recommends using a census of schools to collect exemption data because exemptions are rare events that cluster geographically (8). Since the 2011-12 school year, five states switched to a census from a sample to collect exemption data, increasing representativeness and reliability.

Healthy People 2020 sets a vaccination coverage target of 95\% among kindergartners for the vaccines reported here, as 
TABLE 2. Estimated number and percentage* of children enrolled in kindergarten with reported type of exemption from vaccination, and grace period/provisional enrollment, by state/area ${ }^{\dagger}$ — United States, 2015-16 school year

\begin{tabular}{|c|c|c|c|c|c|c|c|c|c|}
\hline \multirow[b]{2}{*}{ State/Area } & \multirow{2}{*}{$\begin{array}{c}\begin{array}{c}\text { Medical } \\
\text { exemptions }\end{array} \\
\text { No. (\%) }\end{array}$} & \multicolumn{3}{|c|}{ Nonmedical exemptions } & \multicolumn{4}{|c|}{ Any exemption } & \multirow{2}{*}{$\begin{array}{c}\begin{array}{c}\text { Grace period/ } \\
\text { Provisional } \\
\text { enrollment } \\
\end{array} \\
\text { No. (\%) }\end{array}$} \\
\hline & & $\begin{array}{l}\text { No. } \\
\text { religious }\end{array}$ & $\begin{array}{c}\text { No. } \\
\text { philosophic }\end{array}$ & Total No. (\%) & Total No. & $\begin{array}{c}2015-2016 \\
(\%)\end{array}$ & $\begin{array}{c}2014-2015 \\
(\%)\end{array}$ & $\begin{array}{l}\% \text { point } \\
\text { difference }\end{array}$ & \\
\hline Median (\%)" & 0.2 & $N C$ & NC & 1.6 & $N C$ & 1.9 & 1.7 & 0.2 & 2.0 \\
\hline Alabama & $40(0.1)$ & 438 & 一** & $438(0.7)$ & 478 & 0.8 & 0.8 & 0.0 & NA \\
\hline Alaska & $103(1.2)$ & 421 & - ${ }^{* *}$ & $421(4.7)$ & 524 & 5.9 & 5.8 & 0.1 & NA \\
\hline Arizona & $189(0.2)$ & - †† & 3,732 & $3,732(4.5)$ & 3,921 & 4.7 & 4.8 & -0.1 & NA \\
\hline Arkansas & $21(0.1)$ & 160 & 332 & $491(1.2)$ & 512 & 1.3 & 1.3 & 0.0 & NA \\
\hline California & $993(0.2)$ & 3,323 & 10,684 & $14,008(2.4)$ & 15,000 & 2.5 & 2.7 & -0.2 & $26,232(4.4)$ \\
\hline Colorado & $0(<0.1)$ & 198 & 2,765 & $2,963(4.3)$ & 2,963 & 4.3 & 5.4 & -1.1 & $395(0.6)$ \\
\hline Connecticut & $110(0.3)$ & 689 & 一** & $689(1.7)$ & 799 & 2.0 & 1.9 & 0.1 & NA \\
\hline Delaware & $5(<0.1)$ & 131 & -** & $131(1.1)$ & 136 & 1.2 & 1.3 & -0.1 & NA \\
\hline District of Columbia & $44(0.5)$ & 33 & - ${ }^{*}$ & $33(0.4)$ & 77 & 1.0 & 1.1 & -0.1 & NA \\
\hline Florida & $699(0.3)$ & 4,226 & - ${ }^{*}$ & $4,226(1.9)$ & 4,925 & 2.2 & 2.1 & 0.1 & $8,875(4.0)$ \\
\hline Georgia & $145(0.1)$ & 2,315 & - ${ }^{*}$ & $2,315(1.8)$ & 2,460 & 1.9 & 2.1 & -0.2 & $2,672(2.0)$ \\
\hline Hawaii & $70(0.4)$ & 426 & 一** & $426(2.5)$ & 496 & 2.9 & 3.3 & -0.4 & $294(1.7)$ \\
\hline Idaho & $69(0.3)$ & 122 & 1,198 & $1,320(5.8)$ & 1,389 & 6.1 & 6.5 & -0.4 & $537(2.4)$ \\
\hline Illinois§§ & NA & NA & NA & NA & NA & NA & NA & NA & NA \\
\hline Indiana & $395(0.5)$ & 912 & 一** & $912(1.1)$ & 1,035 & 1.2 & 1.1 & 0.1 & NA \\
\hline lowa & $119(0.3)$ & 635 & 一* & 635 (1.5) & 754 & 1.8 & 1.8 & 0.0 & $1,730(4.2)$ \\
\hline Kansas & $97(0.2)$ & 554 & 一* & $554(1.4)$ & 651 & 1.6 & 1.4 & 0.2 & NA \\
\hline Kentucky & $129(0.2)$ & 382 & 一** & $382(0.7)$ & 510 & 0.9 & 0.9 & 0.0 & NA \\
\hline Louisiana & $75(0.1)$ & 28 & 342 & $370(0.6)$ & 445 & 0.8 & 0.6 & 0.2 & NA \\
\hline Maine & $69(0.5)$ & 28 & 515 & $542(4.0)$ & 612 & 4.5 & 4.4 & 0.1 & $169(1.3)$ \\
\hline Maryland & $348(0.5)$ & 601 & 一** & $601(0.8)$ & 949 & 1.3 & 1.2 & 0.1 & NA \\
\hline Massachusetts & $216(0.3)$ & 760 & 一** & $760(1.0)$ & 976 & 1.3 & 1.4 & -0.1 & NA \\
\hline Michigan & $246(0.2)$ & 749 & 3,208 & 3,957 (3.4) & 4,203 & 3.6 & 5.3 & -1.7 & NA \\
\hline Minnesota ${ }^{\S \S}$ & NA & NA & NA & NA & NA & NA & NA & NA & NA \\
\hline Mississippi & $18(<0.1)$ & $-^{\dagger \dagger}$ & 一** & - $^{\dagger+, * *}$ & 18 & $<0.1$ & $<0.1$ & 0.0 & $194(0.5)$ \\
\hline Missouri $\S^{\S}$ & NA & NA & NA & NA & NA & NA & NA & NA & NA \\
\hline Montana & $49(0.4)$ & 390 & 一** & $390(3.4)$ & 439 & 3.8 & 3.9 & -0.1 & $262(2.3)$ \\
\hline Nebraska & $186(0.6)$ & 422 & -** & $422(1.4)$ & 608 & 2.0 & 1.6 & 0.4 & $564(1.9)$ \\
\hline Nevada & $37(0.1)$ & 695 & -** & $695(1.9)$ & 732 & 2.0 & 1.3 & 0.7 & $1,265(3.4)$ \\
\hline New Hampshire & $21(0.2)$ & 288 & - ${ }^{* *}$ & $288(2.4)$ & 309 & 2.6 & 2.9 & -0.3 & $645(5.4)$ \\
\hline New Jersey & $211(0.2)$ & 1,727 & - ${ }^{* *}$ & $1,727(1.6)$ & 1,938 & 1.8 & 1.8 & 0.0 & $1,256(1.1)$ \\
\hline New Mexico & $19(0.1)$ & 346 & - ${ }^{* *}$ & $346(1.2)$ & 365 & 1.3 & 1.2 & 0.1 & $441(1.5)$ \\
\hline $\begin{array}{l}\text { New York (including } \\
\text { New York City) }\end{array}$ & $323(0.1)$ & 1,729 & - $^{* *}$ & $1,729(0.7)$ & 2,052 & 0.9 & 0.8 & 0.1 & NA \\
\hline New York City & $44(<0.1)$ & 394 & 一* & $394(0.4)$ & 438 & 0.4 & 0.4 & 0.0 & NA \\
\hline North Carolina & $141(0.1)$ & 1,240 & 一* & $1,240(1.0)$ & 1,382 & 1.1 & 1.0 & 0.1 & NA \\
\hline North Dakota & $30(0.3)$ & 59 & 240 & $299(3.0)$ & 329 & 3.3 & 2.7 & 0.6 & NA \\
\hline Ohio & $358(0.2)$ & - & —าก & $2,896(2.0)$ & 3,255 & 2.3 & 2.1 & 0.2 & NA \\
\hline Oklahoma & $79(0.1)$ & 236 & 580 & $816(1.5)$ & 895 & 1.6 & 1.5 & 0.1 & NA \\
\hline Oregon & $61(0.1)$ & —१⿻ & —าก & $2,810(6.2)$ & 2,871 & 6.3 & 6.0 & 0.3 & NA \\
\hline Pennsylvania & $511(0.4)$ & 1,212 & 1,408 & $2,620(1.8)$ & 3,132 & 2.2 & 2.1 & 0.1 & $7,365(5.1)$ \\
\hline Rhode Island & $21(0.2)$ & 105 & 一** & $105(0.9)$ & 126 & 1.1 & 1.1 & 0.0 & NA \\
\hline South Carolina & $23(<0.1)$ & 937 & - ${ }^{*}$ & 937 (1.6) & 960 & 1.6 & 1.2 & 0.4 & NA \\
\hline South Dakota & $22(0.2)$ & 175 & 一* ${ }^{*}$ & $175(1.4)$ & 197 & 1.6 & 1.7 & -0.1 & NA \\
\hline Tennessee & $111(0.1)$ & 739 & 一* & $739(0.9)$ & 850 & 1.1 & 1.1 & 0.0 & $1,003(1.3)$ \\
\hline Texas (including Houston) & $821(0.2)$ & —าा & —११ & $5,350(1.4)$ & 6,170 & 1.6 & NA & NA & $11,048(2.8)$ \\
\hline Houston, TX & $90(0.2)$ & —११ & —ฯฯ & $301(0.7)$ & 392 & 0.9 & 0.3 & 0.6 & NA \\
\hline Utah & $88(0.2)$ & 10 & 2,204 & $2,214(4.4)$ & 2,302 & 4.6 & 4.3 & 0.3 & $1,085(2.2)$ \\
\hline Vermont & $9(0.1)$ & 59 & 293 & $352(5.5)$ & 361 & 5.7 & 6.1 & -0.4 & $296(4.6)$ \\
\hline Virginia & $254(0.3)$ & 901 & 一** & $901(0.9)$ & 1,155 & 1.2 & 1.1 & 0.1 & NA \\
\hline Washington & $862(1.0)$ & 267 & 2,886 & $3,153(3.6)$ & 3,878 & 4.5 & 4.6 & -0.1 & $1,730(2.0)$ \\
\hline West Virginia & $35(0.2)$ & - ${ }^{\dagger+}$ & 一** & - $^{\dagger+* * *}$ & 35 & 0.2 & 0.2 & 0.0 & $414(1.9)$ \\
\hline Wisconsin & $244(0.3)$ & 190 & 1,861 & $2,051(2.9)$ & 2,295 & 3.3 & 5.3 & -2.0 & NA \\
\hline Wyoming ${ }^{\S,, * * *}$ & NA & NA & NA & NA & 209 & 2.7 & NA & NA & $0.0(<0.1)$ \\
\hline
\end{tabular}

See table footnotes on the next page. 
TABLE 2. (Continued) Estimated number and percentage* of children enrolled in kindergarten with reported type of exemption from vaccination, and grace period/provisional enrollment, by state/area ${ }^{\dagger}$ — United States, 2015-16 school year

\begin{tabular}{|c|c|c|c|c|c|c|c|c|c|}
\hline \multirow[b]{2}{*}{ State/Area } & \multirow{2}{*}{$\begin{array}{c}\begin{array}{c}\text { Medical } \\
\text { exemptions }\end{array} \\
\text { No. (\%) }\end{array}$} & \multicolumn{3}{|c|}{ Nonmedical exemptions } & \multicolumn{4}{|c|}{ Any exemption } & \multirow{2}{*}{$\begin{array}{c}\begin{array}{c}\text { Grace period/ } \\
\text { Provisional } \\
\text { enrollment }^{\S}\end{array} \\
\text { No. (\%) }\end{array}$} \\
\hline & & $\begin{array}{l}\text { No. } \\
\text { religious }\end{array}$ & $\begin{array}{c}\text { No. } \\
\text { philosophic }\end{array}$ & Total No. (\%) & Total No. & $\begin{array}{c}2015-2016 \\
(\%)\end{array}$ & $\begin{array}{c}2014-2015 \\
(\%)\end{array}$ & $\begin{array}{l}\% \text { point } \\
\text { difference }\end{array}$ & \\
\hline Guam & $0(0.0)$ & 1 & - $* *$ & $1(<0.1)$ & 1 & $<0.1$ & 0.1 & -0.1 & NA \\
\hline N. Mariana Islands & $0(0.0)$ & 0 & 0 & $0(0.0)$ & 0 & 0.0 & 0.0 & 0.0 & NA \\
\hline Puerto Rico & $39(0.1)$ & 57 & - ${ }^{* *}$ & $57(0.2)$ & 97 & 0.3 & 0.2 & 0.1 & NA \\
\hline U.S. Virgin Islands & $0(<0.1)$ & 9 & —** & $9(0.6)$ & 9 & 0.6 & 1.7 & -1.1 & NA \\
\hline
\end{tabular}

Abbreviations: $\mathrm{NA}=$ not available (i.e., not collected or reported to $\mathrm{CDC}$ ); $\mathrm{NC}=$ not calculated.

* Estimates were adjusted for nonresponse and weighted for sampling where appropriate.

† Medical exemptions, nonmedical exemptions, and grace period/provisional enrollment status might not be mutually exclusive. Some children might have both medical and nonmedical exemptions, and some enrolled under a grace period/provisional enrollment might be exempt from one or more vaccinations.

$\S$ Grace period/provisional enrollment data were collected for the first time in 2015-16. Data were reported voluntarily. A grace period is a set number of days during which a student can be enrolled and attend school without proof of complete vaccination or exemption. Provisional enrollment allows a student without complete vaccination or exemption to attend school while completing a catch-up vaccination schedule. In states with one or both of these policies, the estimates represent the number of kindergartners within a grace period, provisionally enrolled, or some combination of these categories.

" Medians calculated from data from 47 states and District of Columbia; states excluded were Illinois, Minnesota, and Missouri. Wyoming was included in only the Any Exemption median. Houston, New York City, Guam, N. Mariana Islands, Puerto Rico, and U.S. Virgin Islands were also excluded.

** Exemptions because of philosophic reasons were not allowed.

${ }^{+\dagger}$ Exemptions because of religious reasons were not allowed.

$\S \S$ State did not report the number of children with exemptions, but instead reported the number of exemptions for each vaccine, which would count some children more than once. Lower bounds of the percentage of children with any exemptions, estimated using the individual vaccines with the highest number of exemptions are the following: for Illinois, $0.2 \%$ with medical exemptions, $1.1 \%$ with religious exemptions, and $1.4 \%$ for any exemptions; for Minnesota, $0.2 \%$ with medical exemptions, $3.1 \%$ with nonmedical exemptions, and $3.4 \%$ for any exemptions; for Missouri $0.2 \%$ with medical exemptions, $1.7 \%$ with religious exemptions, and $1.8 \%$ for any exemptions; and for Wyoming, $0.2 \%$ with medical exemptions and $2.2 \%$ with religious exemptions.

११ Religious and philosophic exemptions were not reported separately.

*** Collected public school data only.

well as for other vaccines. 999 This report found medians for MMR, DTaP, and varicella vaccine all approach the Healthy People 2020 target. A total of 22 states met the Healthy People 2020 target for vaccination with MMR, 20 states met the DTaP vaccination target, and 18 states met the varicella vaccination target.

The findings in this report are subject to at least three limitations, which have been previously reported (3). First, comparability is limited because of variations in states' requirements. Second, representativeness might be negatively affected because of data collection methodologies that miss some schools or students or assess vaccination status at different times. Finally, actual vaccination coverage, exemption estimates, or both might be under- or overestimated because of improper or absent documentation. State-level aggregate grace period/provisional enrollment data were reported to CDC by states that could easily access the data from reporting schools,

\footnotetext{
999 Healthy People 2020 objective IID-10.1 is 4 doses of DTaP vaccine. This report describes compliance with state requirements of 3, 4, or 5 doses of $\mathrm{DTaP}$ vaccine. Among the 50 states and DC, only Nebraska required and reported 3 doses of DTaP vaccine. The IID-10.2 target is $\geq 95 \%$ of kindergartners receiving $\geq 2$ doses of MMR vaccine. Four states required 2 doses of measles-containing vaccine but only 1 dose each of mumps and rubella vaccine. Four states required 2 doses measles and mumps but only 1 dose of rubella vaccine. One state required 2 doses of measles and rubella and zero doses of mumps. The IID- 10.5 target is $\geq 95 \%$ of kindergartners receiving $\geq 2$ doses of varicella vaccine. State-level data with Healthy People 2020 targets are available on SchoolVaxView (http://www.cdc.gov/vaccines/ imz-managers/coverage/schoolvaxview/data-reports/index.html).
}

and represent kindergartners who are identified by the schools as having incomplete vaccination records. The definition of kindergartners under a grace period/provisional enrollment varied by state, so those estimates might not be comparable.

Kindergarten vaccination requirements provide an opportunity for children who are behind on early childhood vaccinations to be vaccinated by school entry. Thorough school vaccination assessments at the state and local levels allow immunization programs to identify schools and communities where focused action could improve vaccination coverage to ensure that more children can benefit from the protection offered by vaccines. Local-level data allow programs to identify schools with undervaccinated students, and public dissemination raises awareness of community vaccination coverage. Immunization programs can use the data to monitor grace period/provisional enrollment levels, in addition to coverage and exemptions, and to work with schools with higher grace period or provisional enrollment rates to ensure all kindergartners receive recommended vaccinations and are protected from vaccine-preventable diseases.

\footnotetext{
${ }^{1}$ National Center for Immunization and Respiratory Disease, Immunization Services Division, CDC; ${ }^{2}$ Association of Schools and Programs of Public Health. Corresponding Author: Ranee Seither, rseither@cdc.gov; 404-639-8693.
} 


\section{References}

1. Orenstein WA, Hinman AR. The immunization system in the United States - the role of school immunization laws. Vaccine 1999;17(Suppl3):S1924. http://dx.doi.org/10.1016/S0264-410X(99)00290-X

2. CDC. SchoolVaxView Interactive! Atlanta, GA: US Department of Health and Human Services, CDC; 2015. http://www.cdc.gov/vaccines/imzmanagers/coverage/schoolvaxview/data-reports/index.html

3. Seither R, Calhoun K, Knighton CL, et al. Vaccination coverage among children in kindergarten-United States, 2014-15 school year. MMWR Morb Mortal Wkly Rep 2015;64:897-904. http://dx.doi.org/10.15585/ mmwr.mm6433a2

4. California Department of Public Health. 2015-2016 Kindergarten Immunization Assessment. Sacramento, CA: California Department of Public Health; 2016. http://www.cdph.ca.gov/programs/immunize/ Documents/2015-16_CA_KindergartenSummaryReport.pdf
5. Clemmons NS, Gastanaduy PA, Fiebelkorn AP, Redd SB, Wallace GS. Measles_-United States, January 4-April 2, 2015. MMWR Morb Mortal Wkly Rep 2015;64:373-6.

6. Fine PEM, Mulholland K. Community immunity [Chapter 71]. In: Plotkin SA, Orenstein WA, Offit PA, eds. Vaccines. 6th ed. Philadelphia, PA: Elsevier Inc., 2013:1395-1412.

7. Michigan Department of Health and Human Services. Immunization waiver information. Lansing, MI: Michigan Department of Health and Human Services; 2016. http://www.michigan.gov/mdhhs/0,5885,7-33973971_4911_4914_68361-344843--,00.html

8. Omer SB, Enger KS, Moulton LH, Halsey NA, Stokley S, Salmon DA. Geographic clustering of nonmedical exemptions to school immunization requirements and associations with geographic clustering of pertussis. Am J Epidemiol 2008;168:1389-96. http://dx.doi.org/10.1093/aje/kwn263 